\title{
Adana ilinde maksimum ve minimum sıcaklıkların gidiş analizi
}

\section{Trend analysis of the maximum and minimum temperature in Adana}

\section{Mete ÖZFIDANER ${ }^{1}$, Duygu ŞAPOLYO² ${ }^{\circledR}$, Fatih TOPALOĞLU $^{2}$}

${ }^{1}$ Alata Bahçe Kültürleri Araştırma Enstitüsü Müdürlüğü

${ }^{2}$ Çukurova Üniversitesi, Ziraat Fakültesi, Tarımsal Yapılar ve Sulama Bölümü

Sorumlu yazar (Corresponding author): M. Özfidaner, e-posta (e-mail): mete.ozfidaner@tarimorman.gov.tr

Yazar(lar) e-posta (Author e-mail): dysapolyo@gmail.com, topaloglu@cu.edu.tr

\section{MAKALE BİLGISİ}

Alınış tarihi 07 Mart 2019

Düzeltilme tarihi 03 Mayıs 2019

Kabul tarihi 27 Mayıs 2019

\section{Anahtar Kelimeler:}

Sicaklık

Mann-Kendall sira korelasyon testi Gidiş

\begin{abstract}
öz
Küresel iklim değișikliği yaygın olarak sıcaklık, yağıș, buharlașma, nem, güneșlenme şiddeti, rüzgâr gibi parametreler üzerinde yapılan çalışmalar sonucunda tespit edilebilmektedir. $\mathrm{Bu}$ parametrelerden hava sıcaklığı ve yağıs, genellikle iklim değisikliği konusunda diğer parametrelere göre daha fazla öneme sahiptir. Bu çalışmada Adana ilinde aylık maksimum ve minimum sıcaklıklardaki olası gidişin belirlenmesi amaçlanmıştır. Bu amaçla Adana'da bulunan 17351 (Adana) numaralı istasyona ait 59 y1llı (1960-2018) minimum ve maksimum sıcaklık verilerinin gidişini belirlemek için parametrik olmayan Mann-Kendall sıra korelasyon testi uygulanmıștır. Çalıșmada elde edilen sonuçlar incelendiği zaman, maksimum sıcaklıklarda 7 defa artış eğilimi belirlenmiştir. Adana istasyonunda önemli artış eğilimi Şubat ve Ağustos ayında görülmüştür. Ayrıca Mayıs-Temmuz ve Kasım aylarında azalma eğilimleri tespit edilmiștir. Yıllık maksimum sıcaklık verilerinde artma eğilimi önemsiz bulunmuştur. Minimum sıcaklık verilerinde ise yıl boyunca artış eğilimleri bulunmuştur. Özellikle yaz ve sonbaharın başlangıcında minimum sıcaklıklarda önemli artışlar belirlenmiştir. Yıılık minimum sıcaklıklarda istasyonda önemli artış gözlemlenmiştir.
\end{abstract}

\section{ARTICLE INFO}

Received 07 March 2019

Received in revised form 03 May 2019

Accepted 27 May 2019

\section{Keywords:}

Temperature

Mann-Kendall rank correlation test Trend

\begin{abstract}
Global climate change can be identified as a result of studies on parameters such as temperature, precipitation, evaporation, humidity, sun intensity, and wind. Temperature and precipitation among these parameters are generally more important than the others on climate change. In this study, determination of possible monthly maximum and minimum temperatures in Adana were aimed. For this purpose the non-parametric Mann-Kendall rank correlation test was applied to determine the trends in minimum and maximum temperatures data 59 years between 1960-2018 collected at 17351 numbered station (Adana). When the results obtained in the study were examined, the maximum temperature in the test results were determined in the tends to increase 7 times. Significant upward trends were observed in Adana station in February and August. Also decreasing trend in May-July and October -November were identified. The annual maximum temperature had not significant increasing trend in the data. In the Adana station, the minimum temperature data was found an upward trend throughout the year. Significant increases were determined at minimum temperatures, especially summer and at the early autumn. A significant increase in the station was observed at annual minimum temperatures.
\end{abstract}

\section{Giriş}

İlkel toplumdan günümüze kadar her alanda yaşanan gelişim, beraberinde birçok sorunu getirmiştir ve getirmeye devam etmektedir. Nüfus artışı, sanayileşme ve kentleşmenin sonucu olarak ortaya çıkan, karbondioksit ve diğer sera gazlarının salınımı gibi insan faaliyetleri; sıcaklığı, yağışları etkilemekte ve küresel iklim değişikliğine neden olmaktadır. Doğal nedenlere bağlı olarak uzun yıllarda yavaş yavaş değişim gösteren iklim, artık günümüzde önemli derecede hissedilebilecek hızlı bir değişim sürecine girmiştir. Geçtiğimiz son 20-30 yıl, en azından 1400 yılından günümüze kadar ki dönemde karşılaşılan en sıcak yıllar olarak gözükmektedir (Türkeş ve ark. 2002). 19. Yüzyılda hız kazanan sanayi devrimi ile birlikte atmosferdeki konsantrasyonu artan ve sera gazları olarak adlandırılan gazların (karbondioksit, metan, azot oksitler, florokloro karbonlar vb.) yeryüzünden yayılan uzun dalga radyasyonu tutması nedeniyle ortalama yüzeysel hava 
sıcaklıklarında belirgin bir artış saptanmıştır. Nitekim geçen yüzyılda 1906 ile 2005 arasında küresel ortalama sıcaklıkta $0.74^{\circ} \mathrm{C}$ 'lik bir artış olduğu belirlenmiştir (IPCC 2007). İklim değişikliği ve küresel ısınma yaygın olarak sıcaklık, yağış, buharlaşma, nem, güneşlenme şiddeti, rüzgâr gibi parametreler üzerinde yapılan çalışmalar sonucunda tespit edilebilmektedir. $\mathrm{Bu}$ parametrelerden hava sicaklığı ve yağış, iklim değişikliği konusunda diğer parametrelere göre daha fazla öneme sahiptir. Sıcaklık ve yağış parametreleri hakkında elde edilen doğru bilgi, su kaynaklarının optimum kullanımı, sel ve kuraklık kontrolü, iklim değişikliğinin değerlendirilmesi ve etkin su yönetimi için önemli bir başlangıç noktasıdır. Su kaynaklarının, yağış üzerine (Özfidaner 2007; Topaloğlu ve Özfidaner 2012; Özfidaner ve ark. 2015, Özfidaner ve ark. 2016), sicaklık üzerine (Salinger ve ark. 2001), Özfidaner ve ark. 2015), akım üzerine (Topaloğlu 2006a, b; Topaloğlu ve ark. 2012), tarımsal faaliyetlerdeki ve arazi kullanımındaki (Gebert ve Krug 2006) değişikliklere karşı son derece hassas olduğunu bildirmişleridir. Türkiye iklim değişikliğinin olumsuz etkileri açısından "risk grubundaki ülkeler” arasında sayılmaktadır (Yamanoğlu 2006; Anonim 2014).

Türkeş ve ark. (2002), çalışmasında iklim değişikliğinde beklenen bir sonucu olarak, geçen on yılda, Akdeniz havzası ve çevresindeki ülkeler için, uzun süreli yüzey hava sıcaklığı değişimleri ve eğilimleri ile Akdeniz havzası boyunca etkili olan atmosfer dolaşımı tipleriyle bağlantılı değişimler ve anomaliler konusunda çok sayıda çalışma yapıldığını belirtmişlerdir. Türkiye için yapılan çalışmaların sonuçlarına göre (Türkeş 1995; Türkes ve ark. 1995; Kadıglu 1997; Tayanç ve ark. 1997), Türkiye'nin büyük bir bölümünde, yıllık ve mevsimlik ortalama yüzey hava sıcaklıklarında, özellikle yaz mevsiminde, genel bir azalma (soğuma) eğiliminin olduğunu belirtmişlerdir. Öte yandan, Türkiye'nin büyük bir bölümünde, mevsimlik minimum sicaklık dizilerinde genel bir artma (1sınma) eğilimi ve maksimum sıcaklık dizilerinde -ilkbahar dışında- genel bir azalma eğiliminin belirgin olduğu bulunmuştur (Türkeş ve ark. 1996). Ancak, bu durum son 10 yılda, özellikle yılın sıcak döneminde, değişmeye başlamıştır (Erlat 1998, 1999; Türkeş 2000). Türkiye ortalama ve maksimum sıcaklıklarda soğuma eğilimleri zayıflamış ve daha az anlamlı hale gelmiştir (Türkeş ark. 2002). Karabulut (2012) Doğu Akdeniz de 1965-2008 yılları arası maksimum ve minimum sıcaklıklarda belirgin artışların gerçekleştiğini ortaya koymaktadır. Ayrıca mevsimsel olarak da önemli artışların meydana geldiğini belirlemişlerdir. Efe ve ark. (2015) Türkiye genelinde yaptıkları çalışmada maksimum ve minimum sicaklıklarda Akdeniz bölgesinde genel olarak azalma eğilimi belirlemişlerdir. Özfidaner ve ark. (2015) çalışmasında Mersin istasyonunda minimum sicaklıklarda bütün aylar da önemli artış, Silifke istasyonunda ise ilkbahar ve yaz aylarında önemli artış belirlemiştir. Maksimum sıcaklıklarda ise Silifke istasyonunda Mayıs ve Ekim aylarında azalma diğer aylarda artış, Mersin istasyonun da ise Mart ayında azalma belirlenirken yaz aylarında önemli artış eğilimleri belirlemiştir. Yıllık maksimum ve minimum sicaklık verilerinde ise iki istasyon içinde önemli artış bulunmuştur.

Dünyada ve Türkiye'de, sicaklık (Kömüşçü 1998; Yue ve Wang 2002; Türkeş 2004; Özfidaner ve ark. 2015), eğilimi üzerine birçok çalışma yapılmıştır. Türkiye sıcaklık gözlemde kullanılan istasyonlarının yeterli sıklıkta kurulmaması, kayıt süresinin istatistiksel çalışmalara imkan verecek ölçüde uzun olmamas1, doğal afetler, insan etkisi, gözlem metodu ve verilerin saklanmasındaki sistematik hatalar gibi birçok faktörün etkisiyle rastgele olma özelliğini kaybederek heterojen özellik göstermeye başlaması gibi nedenlerden dolayı da sıcaklıklarda zamanla görülebilecek artma veya azalma yönündeki gidişlerin de plan, proje ve işletilmesinde göz önüne alınması gerekmektedir. Bu nedenle, bu tür çalışmalara başlamadan önce, verilerin gidiş özelliğinin kontrol edilmesi gereklidir (Topaloğlu 2006a).

$\mathrm{Bu}$ çalışma Adana'da aylık maksimum ve minimum sıcaklıklardaki olası gidişin belirlenmesi amaçlanmıştır. Bu amaçla Adana ilinde bulunan 17351 numaralı istasyona ait 59 y1llık (1960-2018) sıcaklık verisinin gidişini belirlemek için parametrik olmayan Mann-Kendall sira korelasyon testi uygulanmıştır.

\section{Materyal ve Yöntem}

\subsection{Materyal}

$\mathrm{Bu}$ çalışmada; Akdeniz bölgesinde bulunan, Meteoroloji Genel Müdürlüğü (MGM) tarafindan işletilen Adana istasyonunun 1960-2018 yılları arasında ölçülen aylık minimum ve maksimum sıcaklık verileri kullanılmıştır. Bu kayıt döneminin seçilmesinin temel nedeni, aynı kayıt dönemine sahip en fazla sayıda istasyonun bu yıllar arasında olmasıdır.

\subsection{Yöntem}

Bir yağış ya da sıcaklık gözlem istasyonunun verileri zaman içinde sürekli artar veya azalırsa serinin bir gidişe sahip olduğu söylenebilir. Yağış yada sıcaklık verilerinin toplanış sırası ile aldığı değerler arasında önemli bir korelasyonun olup olmadığını belirleyen gidiş analizi için geliştirilmiş Spearman, ve Mann-Kendall sıra korelasyon testleri gibi bir çok parametrik olmayan testler mevcuttur (Topaloğlu 2006a). Bu çalışmada doğrusal ve doğrusal olmayan gidişlerin ortaya çıkarılmasında etkili, basit ve dağılımdan bağımsız olan ve sıra istatistiklerine dayanan bir yaklaşım olan Mann-Kendall sıra korelasyon testi kullanılmıştır.

\subsubsection{Mann-Kendall sira korelasyon testi}

Parametrik olmayan Mann-Kendall istatistik testi hidrometeorolojik zaman serilerinde meydana gelebilecek artma veya azalma yönündeki gidişlerin istatistiksel önemini test etmede oldukça sık kullanılan bir testtir. Bu gidiş testi $\mathrm{i}=1, \ldots, \mathrm{n}-1$ 'e kadar sıralanmış olan bir xi veri setine ve $\mathrm{j}=\mathrm{i}+1, \ldots$, n'e kadar sıralanmış olan bir xj veri setine uygulanır. Her bir sıralanmış rakam xi bir referans noktası olarak kullanılır ve diğer sıralanmış veri grubu xj ile aşağıdaki denklemde verildiği gibi kıyaslanır.

$$
\operatorname{sgn}(x)=\left\{\begin{array}{cl}
1 & ; x_{j}>x_{i} \\
0 & ; x_{j}=x_{i} \\
-1 & ; x_{j}<x_{i}
\end{array}\right.
$$

Mann-Kendall test istatistiği $\mathrm{S}$ ise Denklem ile hesap edilebilir.

$$
S=\sum_{i=1}^{n-1} \sum_{j=i+1}^{n} \operatorname{sgn}\left(x_{j}-x_{i}\right)
$$


Denklemde $n$ yıl olarak veri uzunluğudur. S değeri ise $n \geq 8$ olduğunda aşağıda verilen ortalama ve varyans ile yaklaşık olarak normal dağılım gösterir.

$$
\begin{aligned}
& E[S]=0 \\
& \operatorname{Var}(S)=\frac{n(n-1)(2 n+5)-\sum_{i=1}^{n} t_{i}(i)(i-1)(2 i+5)}{18}
\end{aligned}
$$

Burada, $t_{i}$ değeri i uzunluğundaki bir seride bağlı gözlemleri göstermektedir. Eşitlikteki toplama terimi sadece veride bağlı gözlem olduğunda kullanılır. Standartlaştırılmış Mann-Kendall istatistiği Z ise Denklem'te verildiği gibi hesaplanabilmekte ve seride gidiş (trend) yoktur sıfır hipotezi (H0) varsayımı altında ortalaması sıfır, varyansı bir olan standart normal dağılım göstermektedir.

$$
Z=\left\{\begin{array}{cc}
\frac{S-1}{\sqrt{\operatorname{Var}(S)}} & ; S>0 \\
0 & ; S=0 \\
\frac{S+1}{\sqrt{\operatorname{Var}(S)}} & ; S<0
\end{array}\right.
$$

Sıfır hipotezi Mann-Kendall test istatistiği -ztablo, $1-\alpha / 2 \leq \mathrm{Z} \leq$ ztablo, $1-\alpha / 2$ ise kabul edilmektedir. Artı $\mathrm{Z}$ değeri akımlarda artışı gösterirken, eksi $Z$ değeri azalışa işaret etmektedir.

\section{Bulgular}

Akdeniz bölgesinde bulunan ve verileri istatistiksel analize imkan verecek ölçüde yeterli olan sıcaklık gözlem istasyonunun 59 yıllık (1960-2018) aylık maksimum ve minimum sicaklık verilerindeki gidişi $\% 5$ önem düzeyinde Mann-Kendall sıra korelasyon testi $(-1.96 \leq \mathrm{Z} \leq 1.96)$ ile test edilmiş ve sonuçlar Çizelge 1'de verilmiştir. Adana sıcaklık gözlem istasyonunun maksimum ve minimum sicaklık verilerine uygulanan MannKendall sira korelasyon testi sonucunda maksimum ve minimum sıcaklılarda artış eğilimleri bulunmuştur.

\subsection{Minimum sıcaklıkların Mann-Kendall analiz sonuçları}

Adana istasyonunda 1960-2018 y1llarına ait minimum sıcaklık verilerinin gidiş analiz sonuçları Cizelge 1 'de verilmiştir. Minimum sicaklık verilerinde \%5 önem seviyesinde artış eğilimleri görülmektedir. Adana istasyonunda bütün aylar da artış belirlenirken, istatistiksel olarak Mart ve Mayıs-Ekim ayları arasında istatistiki açıdan önemli artışlar belirlenmiştir. Adana istasyonunda Ağustos ayında $0.063^{\circ} \mathrm{C}$ lik bir artış eğiliminin olduğu tespit edilmiştir. Ayrıca yıllık ortalama minimum sicaklık verilerinin analizi sonucunda istatistiksel olarak önemli artışın meydana geldiği Çizelge 1'den görülmektedir. Yıllık bazda sıcaklıkta $0.037^{\circ} \mathrm{C}$ artışın olacağ görülmektedir. Karabulut (2012), yılında yaptığı çalışmasında 1965-2008 tarihleri arasındaki yıllık minimum sıcaklık değerlerinde \%5 önem seviyesinde istatistiksel olarak önemli artış belirlemiş ve çalışmamız ile paralel sonuçlar bulmuştur. Türkeş ve ark. (2002), çalışmalarında yıllık minimum sıcaklık değerlerinin Adana istasyonu için istatistiksel olarak önemli artma eğiliminde olduğunu belirlemişlerdir. Buna karşılık Efe ve ark. (2015), yaptıkları çalışmada 1950-2013 yılları arasındaki yıllık minimum sıcaklık verilerinde azalma eğilimi tespit etmişlerdir. Yaz sıcaklıkları, ilkbaharda olduğu gibi, artma eğilimi göstermiştir. Çizelge 1 incelendiği zaman görülecektir ki minimum sıcaklıklar da azalma eğilimleri belirlenmemiştir. Buna karşın Karabulut (2012) yaptığı çalışmada Aralık, Şubat ve Kasım ayların da azalma eğilimleri belirlemiştir. Bu aylardaki faklılığın nedeni incelenen verilerin farklı tarihlerde olmasından dolayı olabilir.

Çizelge 1. Minimum sıcaklıların Mann-Kendall test analizi sonuçları (1960-2018).

\begin{tabular}{|c|c|c|}
\hline Aylar & MK testi & Değişim miktarı $\left({ }^{\circ} \mathrm{C}\right)$ \\
\hline Ocak & $0.24 \uparrow$ & 0.005 \\
\hline Şubat & $0.99 \uparrow$ & 0.018 \\
\hline Mart & $3.20 * \uparrow *$ & 0.065 \\
\hline Nisan & $1.73 \uparrow$ & 0.029 \\
\hline Mayıs & $2.92 * \uparrow *$ & 0.037 \\
\hline Haziran & $3.40 * \uparrow *$ & 0.036 \\
\hline Temmuz & $4.52 * \uparrow^{*}$ & 0.054 \\
\hline Ağustos & $4.59 * \uparrow *$ & 0.063 \\
\hline Eylül & $3.22 * \uparrow *$ & 0.057 \\
\hline Ekim & $2.73^{*} \uparrow^{*}$ & 0.056 \\
\hline Kasım & $0.62 \uparrow$ & 0.016 \\
\hline Aralık & $0.94 \uparrow$ & 0.019 \\
\hline Y1llık & $5.20 * \uparrow *$ & 0.037 \\
\hline
\end{tabular}

Table 1. Result of the Mann-Kendall test for minimum temperatures (1960-2018).

Şekil 1'de Adana istasyonu yıllık minimum sicaklık değerlerine uygulanan Mann-Kendall sira korelasyon mertebe testi sonucunda (ut) değerleri 1982 yllından itibaren \%5 önem seviyesinde istatistiksel olarak artış olmuş ve bu artışlar kritik değer olan 1.96 değerinin üzerinde 2006 yılından itibaren belirlenmiş olup istatistiksel olarak önemli artışları göstermektedir. Türkeş ve ark. (2002), Adana istasyonu için 1968 yılından itibaren artış eğilimleri belirleşmişlerdir. Bunun nedeni olarak kullandıkları veri aralığının 1930-2000 yılları arasında olmasından kaynaklanmaktadır. Efe ve ark. (2015), çalışmasında Türkiye genelinde yıllık minimum sıcaklıklarda 1992 yılından itibaren artış eğilimi olmasına rağmen 2005 yılından itibaren artış eğiliminin gerçekte başladığı nokta olarak belirlemişlerdir.

\subsection{Maksimum sıcaklıkların Mann-Kendall analiz sonuçları}

Adana istasyonunda 1960-2018 yıllarına ait maksimum sıcaklık verilerinin gidiş analiz sonuçları Çizelge 2'de verilmiştir. Maksimum sicaklık verilerinde \%5 önem seviyesinde genel olarak artış eğilimleri görülmektedir. Çizelge 2'den görüleceği gibi maksimum sıcaklık sonuçlarında minimum sicaklıklara göre farklılıklar meydana gelmiştir. Adana istasyonunda 7 ay artış 5 ay azalış eğilimi belirlenmiştir Adana istasyonunda Mayıs-Temmuz ve Ekim, Kasım aylarında azalma eğilimleri belirlenmiştir. Maksimum sicaklık değerlerinde Şubat ve Ağustos ayında istatistiksel olarak önemli artış eğilimi belirlenmiştir. Şubat ayında meydana gelen artma eğilim değeri $0.041^{\circ} \mathrm{C}$ olarak belirlenirken, Ağustos ayında ise bu değer $0.036^{\circ} \mathrm{C}$ olarak bulunmuştur. Diğer aylarda ise maksimum sıcaklılarda artış bulunmuştur. Yıllık maksimum sıcaklık verilerinde ise önemli olmayan azalma görülmüştür. 
Çizelge 2. Maksimum sıcaklıların Mann-Kendall test analizi sonuçları (1960-2018).

Table 2. Result of the Mann-Kendall test for maximum temperatures (1960-2018).

\begin{tabular}{lccc}
\hline Aylar & MK Testi & Değişim miktarı $\left({ }^{\circ} \mathbf{C}\right)$ \\
\hline Ocak & $0.67 \uparrow$ & 0.007 \\
Şubat & $2.34 \uparrow^{*}$ & 0.041 \\
Mart & $1.20 \uparrow$ & 0.022 \\
Nisan & 1.79 & $\uparrow$ & 0.037 \\
Mayis & -1.13 & -0.020 \\
Haziran & $-0.27 \downarrow$ & -0.006 \\
Temmuz & $-0.36 \downarrow$ & -0.006 \\
Ağustos & 2.41 & $\downarrow$ & 0.036 \\
Eylül & 0.67 & $\uparrow$ & 0.011 \\
Ekim & $-0.06 \downarrow$ & -0.0001 \\
Kasım & $-0.38 \downarrow$ & -0.007 \\
Aralık & $0.14 \uparrow$ & 0.0001 \\
Y1llık & $-0.48 \downarrow$ & -0.003
\end{tabular}

*: \%5 önem düzeyinde istatistiksel olarak önemlidir.
Y1llık bazda meydana gelen değişiklik ise $0.003^{\circ} \mathrm{C}$ olarak tespit edilmiştir. Karabulut (2012) çalışmasında \%5 önem seviyesinde artış belirlerken, \%10 önem seviyesinde önemli artış olarak belirlemiştir. Karabulut (2012), çalışmasında Mart ve Haziran ayı için azalma eğilimini, istatistiksel olarak artma eğilimini ise benzer olarak Ağustos ayında tespit etmiştir. Türkeş ve ark. (2002), çalışmalarında 1929-1999 yılları yıllık maksimum sıcaklık verilerinde önemsiz artma eğilimi tespit etmişlerdir.

Şekil 2'de Adana istasyonu yıllık maksimum sicaklık değerlerine uygulanan Mann-Kendall sira korelasyon mertebe test sonucunda (ut) değerleri 1960-1977 arasında azalma eğilimleri görülmüştür. 1977 yılından itibaren yıllık maksimum s1caklılarda artma yönünde eğilim söz konusudur. 1977-2014 yılları arasında artış eğilimi istatistiki olarak önemli olmamak üzere devam etmiștir. 2005 yılından sonra yıllık maksimum sıcaklıklarda azalma yönünde eğilim göstermiştir. Türkeş ve ark. (2002) Adana istasyonu için yıllık maksimum sicaklılarda önemsiz artış eğilimleri belirleşmişlerdir. Efe ve ark. (2015), çalışmasında Türkiye genelinde yıllık maksimum sicaklıklarda 2008 yllından itibaren artış eğiliminin başladığı nokta olarak belirlemişlerdir.

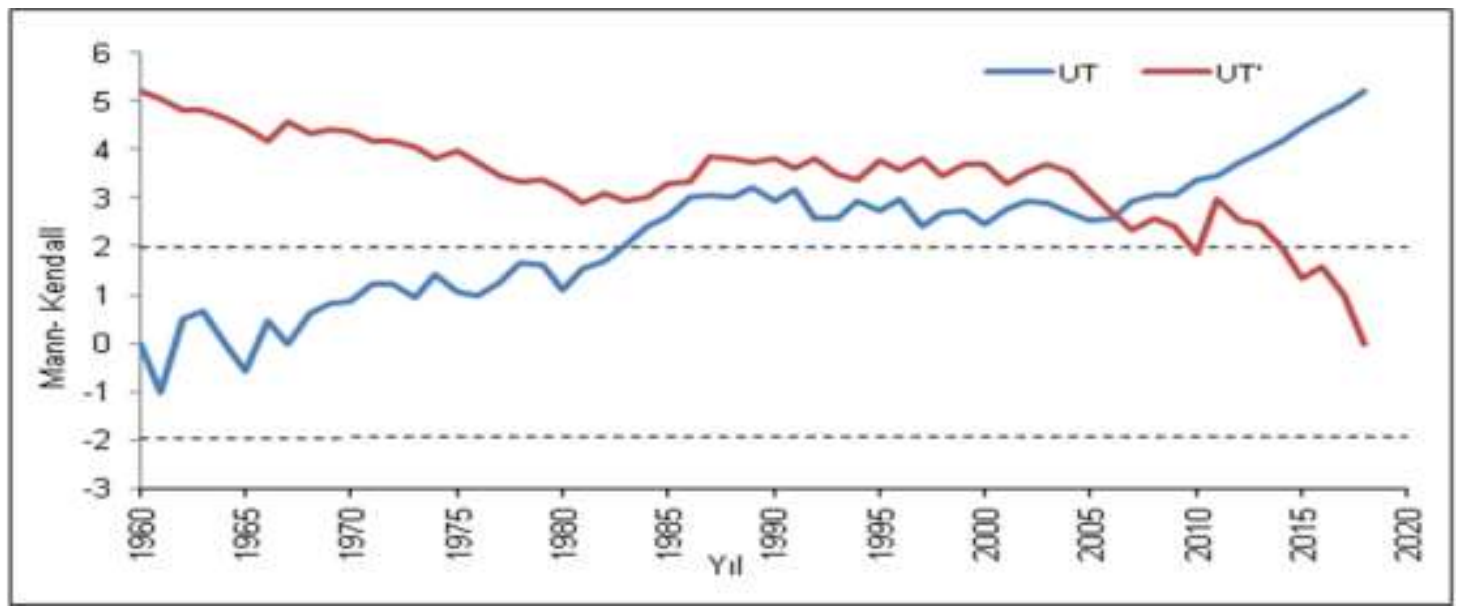

Şekil 1.Yıllık minimum sıcaklıkların Mann-Kendall istatistiği (--- \%5 önem seviyesini temsil etmektedir).

Figure 1. Mann-Kendall statistics of the annual minimum temperatures (-----5\% represents the importance level).

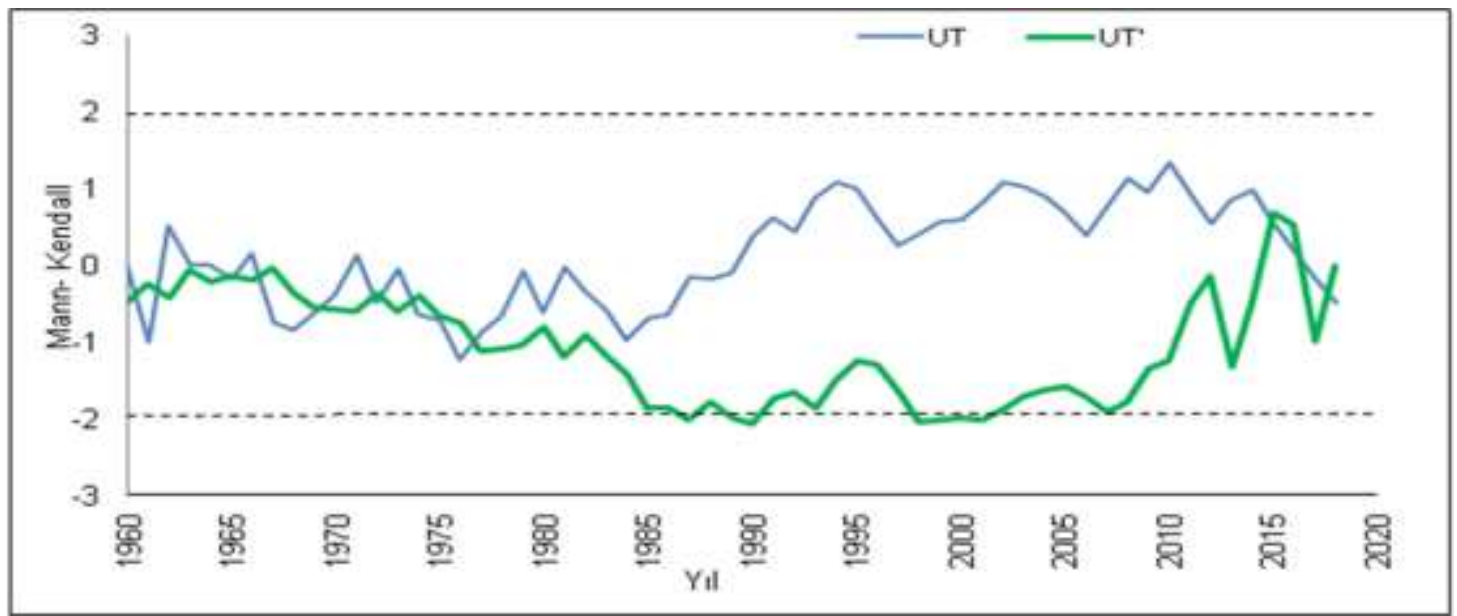

Şekil 2. Adana istasyonu yıllık maksimum sıcaklıkların Mann-Kendall istatistiği (--- \%5 önem seviyesini temsil etmektedir).

Figure 2. Mann-Kendall statistics of the annual maximum temperatures (------5\% represents the importance level). 


\section{Sonuç}

Adana istasyonunda (1960-2018) yılları arasındaki aylık maksimum ve minimum sicaklıklardaki gidiş, parametrik olmayan Mann-Kendall sıra korelasyon testi kullanılarak belirlenmiştir. Gidiș analizi sonucunda maksimum sıcaklıklarda 7 defa artış eğilimi belirlenmiştir. Önemli artış eğilimleri Adana istasyonunda Ağustos ve Şubat ayında görülmüştür. Ayrıca Mayıs- Temmuz ve Ekim- Kasım aylarında azalma eğilimleri tespit edilmiştir. Y1llık maksimum sıcaklık verilerinde önemsiz azalma eğilimi bulunmuştur. Minimum sıcaklık verilerinde ise Adana istasyonunda yıl boyunca artış eğilimleri bulunmuştur. Özellikle yaz aylarının başlarında ve sonbaharın başlangıcında minimum sıcaklıklarda önemli artışlar belirlenmiştir. Yıllık minimum sıcaklıklarda Adana istasyonda önemli artış gözlemlenmiştir. Türkeş ve ark. (2002), Türkiye genelinde minimum sıcaklılarda önemli artışların olabileceğini belirtmiştir. Karabulut (2012), çalıșmasında Adana istasyonu için çalışmamıza paralel sonuçlar ortaya koymuştur.

Sonuç olarak, şehirsel özelliği gösteren Adana istasyonu gibi yerlerde önemli sıcaklık artışlarına rastlanırken bu istasyonlara komşu olan bazı istasyonlarda dikkate değer sıcaklık değişimlerinin görülmemesi, bu alanların daha çok kır özelliği göstermesiyle alakalı olabilir. Nitekim şehirlerde değişen radyasyon dengesi daha sıcak ortamların oluşmasına dolayısıyla kentsel 1S1 adalarının meydana gelmesine yol açmaktadır. Şehirlerdeki konutlarda ve sanayide artan enerji tüketimi, yeşil alanların azalması, yüzey neminin azalması, yoğunlaşan trafik, asfalt ve beton gibi yapay yüzeylerin radyasyon dengesini değiştirmesi, iklim elemanlarının alansal ve zamansal dağılışında farklılaşmaların meydana gelmesine yol açmaktadır (Çiçek ve Doğan 2005).

\section{Kaynaklar}

Anonim (2014) Ankara Ticaret Odası (ATO) Küresel ısınma kıskacında Türkiye http://www.atonet.org.tr/yeni/index.php?p=303\&l=1. Erişim 2016.

Çiçek İ, Doğan U (2005) Ankara'da şehir ısı adasının incelenmesi. Coğrafi Bilimler Dergisi 3(1): 57- 72.

Efe B, Toros H, Deniz A (2015) Türkiye geneli yağış ve sıcaklık verilerinde eğilimler ve salınımlar. VII. Atmospheric Science Symposium.

Erlat E (1998) 1998: Küresel kayıtlardaki en sıcak yaz mı? Cumhuriyet Bilim Teknik Dergisi 602: 10.

Erlat E (1999) İzmir'de maksimum sicaklıklar ve sıcak dalgaları. Ege Cografya Dergisi 10: 125-148.

Gebert WA, Krug WR (1996) Streamflow trends in Wisconsin's driftless area. Water Resources Bulletin 32(4): 733-744.

IPCC (2007) Summary for policymakers. In: Climate change 2007: The physical science basis. Contribution of working group I to the fourth assessment report of the intergovernmental panel on climate Ccange [Solomon S, D Qin, M Manning, Z Chen, M Marquis, KB Averyt, M Tignor and HL Miller (Eds.)]. Cambridge University Press, Cambridge, United Kingdom And New York, NY, USA.

Kadioglu M (1997) Trends in surface air temperature data over Turkey. International Journal of Climatology 17: 511-520.

Karabulut M (2012) Doğu Akdeniz'de ekstrem maksimum ve minimum sıcaklıkların trend analizi. KSÜ Doğa Bil. Der. Özel Sayı, 2012 3744.

Kömüşçü AÜ (1998) An Analysis of the fluctuations in the long-term annual mean air temperature data of Turkey. International Journal of Climatology 18(2): 199-213.
Özfidaner M (2007) "Türkiye yağış verilerinin trend analizi ve nehir akımları üzerine etkisi”, Çukurova Üniversitesi, Fen Bilimleri Enstitüsü, Yüksek Lisans Tezi, Adana, s. 73.

Özfidaner M, Şapolyo D, Topaloğlu F, Baydar A (2015) Mersin ilinde maksimum ve minumum sıcaklıların gidiş analizi. 12. Kültürteknik Sempozyumu Antalya.

Özfidaner M, Şapolyo D, Topaloğlu F (2016) İç Anadolu bölgesi yağış verilerinin gidiş analizi. Nevşehir Bilim ve Teknoloji Dergisi TARGID Özel Sayı 161-168 2016 doi: 10.17100/nevbiltek.33972.

Salinger MJ, Griffths GM (2001) Trends in New Zealand daily temperature and rainfall extremes. International Journal of Climatology 21: 1437-1452.

Tayanç M, Karaca M, Yenigün O (1997) Annual and seasonal air temperature trend patterns of climate change and urbanization effects in relation to air pollutants in Turkey. Journal of Geophysical Research 102: 1909-1919.

Topaloğlu F (2006a) Regional trend detection of Turkish river flows. Nordic Hydrology, 37 (2): 165-182.

Topaloğlu F (2006b) Trend detectıon of streamflow variables in Turkey. Fresenıus Environmental Bulletın 15(7): 644-653.

Topaloğlu F, Özfidaner M (2012) "Regional trends of precipitation in Turkey", Fresenius Environmental Bulletin vol. 21, pp. 2908-2915.

Topaloglu F, Irvem A, Özfidaner M (2012) Re-evaluation of trends in annual streamflows of turk1sh rivers for the period 1968-2007. Fresenius Environmental Bulletin Vol.21 No.8 pp. 2043-2050.

Türkeş M (1995) Türkiye'de yıllık ortalama hava sıcaklıklarındaki değişimlerin ve eğilimlerin iklim değişikliği açısından analizi. Çevre ve Mühendislik Dergisi, Ankara, 9: 9-15.

Türkeş M, Sümer UM, Kılıç G (1995) Variations and trends in annual mean air temperatures in Turkey with respect to climatic variability. International Journal of Climatology 15: 557-569.

Türkeş M, Sümer UM, Kılıç, G (1996) Observed changes in maximum and minimum temperatures in Turkey. International Journal of Climatology 16: 463-477.

Türkeş M (2000) Küresel 1sınma: yeni rekorlara doğru. Cumhuriyet Bilim Teknik Dergisi 673: 20-21.

Türkeş M, Sümer UM, Demir İ (2002) Türkiye'nin günlük ortalama, maksimum ve minimum hava sıcakları ile sıcaklık genişliğindeki eğilimler ve değişiklikler. Prof. Dr. Sırrı Erinç Anısına Klimatoloji Çalıştayı, 11-13 Nisan 2002, İzmir, 89-106.

Türkeş M, Sümer UM (2004) Spatial and temporal patterns of trends and variability in diurnal temperature ranges of Turkey. Theoretical and Applied Climatology 77: 195-227.

Yamanoğlu GÇ (2006) Türkiye'de küresel ısınmaya yol açan sera gazı emisyonlarındaki artış ile mücadelede iktisadi araçların rolü. Yüksek Lisans Tezi, Ankara Üniversitesi, Ankara.

Yue S, Wang CY (2002) Regional streamflow trend detection with consideration of both temporal and spatial correlation. International Journal of Climatology 22: 933-946. 